\title{
Use of Bézier curves in the design of the displacement law of the cam-follower mechanism: Von Mises effective Stress
} Uso de las curvas de Bézier en el diseño de la ley de desplazamiento del mecanismo de leva - seguidor: Esfuerzo efectivo de Von Mises

\author{
Carlos Humberto Acevedo-Peñaloza ${ }^{1 a}$, Sergio Andrés Ramón-Ramón ${ }^{1 b}$, Víctor Jhoel \\ Bustos-Urbano ${ }^{2}$
}

\begin{abstract}
${ }^{1}$ Grupo de Investigación Ingeniería y Desarrollo Social (INDES), Programa de Ingeniería Mecánica, Universidad Francisco de Paula de Santander, Colombia. Orcid: ${ }^{\mathrm{a}}$ 0000-0002-5049-8754, ${ }^{\mathrm{b}}$ 0000-0002-1310-9182.

Emails: ${ }^{\text {a }}$ carloshumbertoap@ufps.edu.co, ${ }^{\mathrm{b}}$ sergioandresrra@ufps.edu.co

${ }^{2}$ Grupo de investigación en Geología, Geotecnia y Minería (GEOENERGIA), Programa de Ingeniería de Minas, Universidad Francisco de Paula de Santander, Colombia. Orcid: 0000-0001-6954-2260.

Email: victorjhoelbu@ufps.edu.co
\end{abstract}

Received: 20 February 2020. Accepted: 10 June 2020. Final version: 1 July 2020.

\begin{abstract}
Designing cams by Bézier Curves has become increasingly common, since the mathematical development of this method is less complex. Bezier curves are Bernstein-based polynomials under a unitary domain, and in that sense, this article presents the design of a cam using Bezier curves of degrees 5, 7 and 9. And beyond, this article seeks to show the variation of the effective effort of Von Mises in a cam-follower mechanism composed of a disc cam and a roller follower with translation movement and force closure. The expressions that allow determining the variation of Von Mises' effort for each of the curves used are presented. This variation is presented by means of graphs in which it is observed that as the degree of the curve increases, the magnitude of the efforts is greater, and this increases the probability of failure in the mechanisms. In addition, it was found that there is an inverse relationship between the stress and the radius of the primary circle of the cam.
\end{abstract}

Keywords: Bezier curves; cam design; distortion energy; Von Mises stress; cam-follower mechanism; Bernstein base polynomials; contact theory.

\section{Resumen}

Diseñar levas por Curvas de Bézier se ha hecho cada vez más frecuente, puesto que el desarrollo matemático de este método es menos complejo. Las curvas de Bézier son polinomios de base Bernstein bajo un dominio unitario, y en ese sentido, este artículo presenta el diseño de una leva se mediante curvas Bézier de grados 5, 7 y 9. Y más allá, este artículo busca mostrar la variación del esfuerzo efectivo de Von Mises en un mecanismo leva-seguidor compuesto por una leva de disco y un seguidor de rodillo con movimiento de traslación y cierre de fuerza. Se plantean las expresiones que permiten determinar la variación del esfuerzo de Von Mises para cada una de las curvas utilizadas. Esta variación se presenta mediante gráficos en los que se observa que a medida que aumenta el grado de la curva, la magnitud de los esfuerzos es mayor y esto aumenta la probabilidad de fallas en los mecanismos. Además, se encontró que hay una relación inversa entre el esfuerzo y el radio del círculo primario de la leva.

ISSN Printed: 1657 - 4583, ISSN Online: 2145 - 8456, CC BY-ND 4.0 (c) (1) $\ominus$

How to cite: C. Acevedo, S. Ramón, V. Bustos, "Use of Bézier curves in the design of the displacement law of the cam-follower mechanism: Von Mises effective Stress," Rev. UIS Ing., vol. 19, no. 4, pp. 19-26, 2020, doi: https://doi.org/10.18273/revuin.v19n4-2020002 
Palabras clave: curvas de Bézier; diseño de levas; energía de distorsión; esfuerzo de Von Mises; mecanismo levaseguidor; polinomios de base Bernstein; teoría de contacto.

\section{Introduction}

Cam-follower mechanisms constantly experience stresses resulting from contact between the elements, such stresses occurring periodically during the operating cycle of the mechanism increase the probability that the system will fail due to fatigue [1]. In cam-follower systems, the elements are under the action of combined stresses due to the condition of rotation and slip that occurs during the operating cycle. To evaluate the effect of these stresses on the contact elements, it is necessary to establish a failure theory that allows determining the extent to which the stresses affect the integrity of the mechanism [2].

Due to the nature of the operation of the cam - tracker mechanisms, the materials used for their manufacture are ductile and with isotropic properties; therefore, the failure criteria must satisfy these application conditions [3]. Meanwhile, the most common failure criteria for ductile materials in the academic environment are the maximum shear criteria and the maximum energy criterion of distortion; the first criteria establish that the failure of a ductile element is caused by shear stresses that cause the sliding of the material along oblique surfaces, while the second attempts to determine the amount of energy that could generate changes in the shape of the element [4].

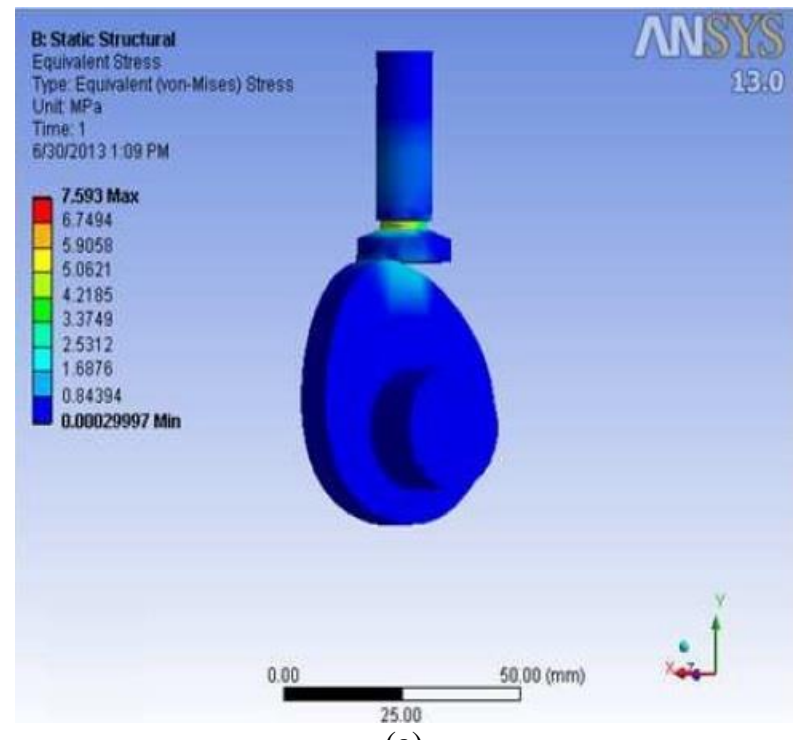

(a)
The article shows the distortion energy criteria to evaluate the effect of the combined stresses on the mechanism. The criterion of maximum distortion energy is also known as Von Mises' criterion; this theory groups the stresses exerted at one point and presents them as an effective stress, which is a tensile stress equivalent to the distortion energy generated by the combined stresses.

The figure 1 shows the distribution of equivalent stresses (Von Mises) for a cam-follower mechanism, generated by means of finite elements, one of the most used numerical tools for engineering design [5].

In the development of the paper is related the variables involved in the calculation of the effective stress of a mechanism formed by a disc cam with roller follower which has a translation movement. The curve that describes the position of the follower during an operation cycle has been made by means of Bézier curves, spline curve [6].

\section{Materials and methods}

To calculate the effective stress, it is necessary to determine the main stresses experienced by the mechanism during its operation, which involves the geometric characteristics of the elements, the operating conditions of the mechanism and the contact theory that allows obtaining the magnitudes of the stresses exerted in the system [7].

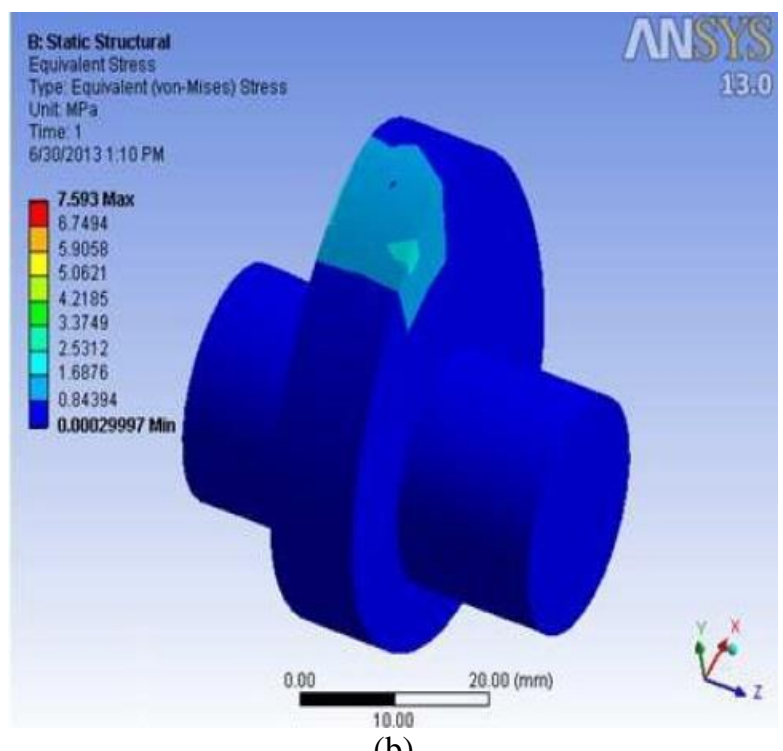

(b)

Figure 1. Distribution of equivalent stresses (Von Mises) for a cam-follower mechanism [9]. 
Figure 2 presents a flow diagram in which the variables involved in the calculation of the effective stress are presented, as well as some considerations that must be considered in order to select the appropriate contact theory for the case in study.

From figure 2 it can be seen that the starting point in the process to determine the effective stress in a system cam - follower, is to establish the law of displacement, which represents the position of the tracker during a complete turn of cam, in the case of disc cams with translation tracker, this parameter is directly related to the final shape of the cam [8].

For the design of the displacement law of the mechanism evaluated in the paper, Bézier curves of grade 5, 7 and 9 have been used. The Bézier curves are Bernstein base polynomials under a unitary domain, they are functions recently used to design the movement of the follower [10], [11].
Among the qualities of this type of curves are their symmetry, their positive form and their numerical stability which makes them recommendable for the construction of displacement curves and their derivatives [12]. The expression that defines a bezier curve has the form shown in equation (1).

$$
\begin{aligned}
B_{i}^{n}(u)=\left(\begin{array}{c}
n \\
i
\end{array}\right) u^{i} & (1-u)^{n-1} \\
& =C_{n}^{i} u^{i}(1-u)^{n-1 ;} \quad i \\
& =0, \ldots \ldots, n
\end{aligned}
$$

In order to develop the functions proposed in the design of the displacement law, it is necessary to introduce the characteristics of the mechanism, physical and inertial parameters [13]. The geometric and operating properties of the evaluated mechanism are presented in table 1 .

The application of contact theory to the cam-follower mechanism begins by determining the pressure angle along the rotation of the cam, and then calculating the contact force experienced by the mechanism [6].

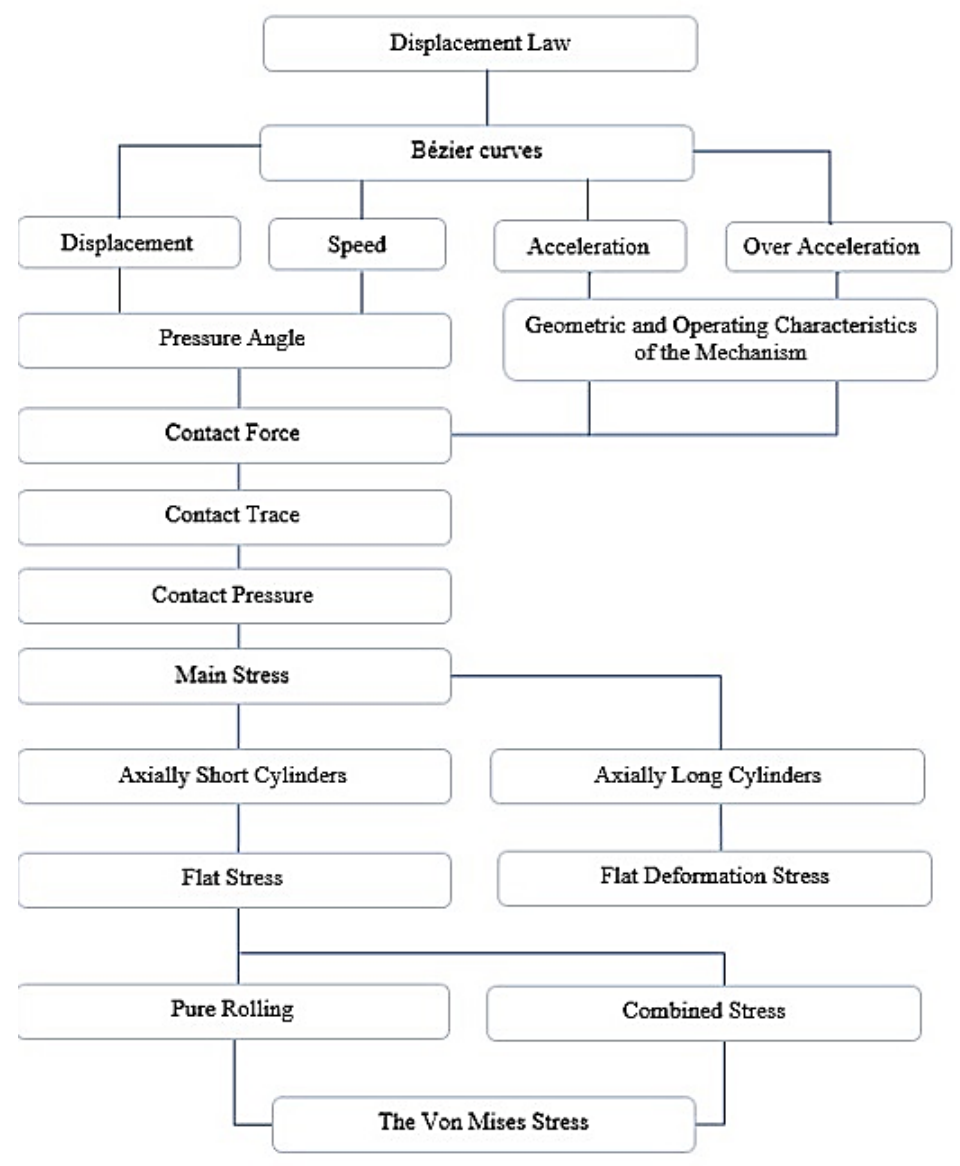

Figure 2. Flowchart to calculate the effective stress in a cam-follower mechanism. 
Table 1. Characteristics of the model mechanism.

\begin{tabular}{|c|c|}
\hline Characteristics of the model & Value \\
\hline Maximum tracker lift $l$ & $0,01 \mathrm{~m}$ \\
\hline Cam mass $m_{l}$ & $0,5 \mathrm{~kg}$ \\
\hline Tracker mass $m_{r}$ & $0,2 \mathrm{~kg}$ \\
\hline Roller radius $R_{r}$ & $0,01 \mathrm{~m}$ \\
\hline Primary circle radius $R_{0}$ & $0,02 \mathrm{~m}$ \\
\hline Cam thickness $l$ & $0,01 \mathrm{~m}$ \\
\hline Poisson's ratio $v$ & 0,3 \\
\hline Equivalent rigidity factor $k$ & $800 \mathrm{~N} / \mathrm{m}$ \\
\hline System preload $F_{p l}$ & $1500 \mathrm{~N}$ \\
\hline Damping constant $c$ & $0,06 \mathrm{c}_{\mathrm{c}}$ \\
\hline Angular cam speed $\omega$ & $20 \pi \mathrm{rad} / \mathrm{seg}$ \\
\hline
\end{tabular}

As illustrated in Figure 2, the pressure angle involves the displacement and acceleration function of the Bézier curve, as well as a characteristic of the mechanism. The pressure angle in a follower cam system is defined by equation (2).

$$
\varnothing=\tan ^{-1}\left(\frac{s^{\prime}(\theta)}{s(\theta)+R_{o}}\right)
$$

The factors $s(\theta), s^{\prime}(\theta)$ and $R_{o}$ represent the displacement of the follower, the speed of the follower and the radius of the primary circle of the cam, respectively. For the pressure angle it must be considered that a value greater than $30^{\circ}$ may cause additional stresses to the follower's rod, therefore it is recommended not to exceed this value [14].

\subsection{Theory of contact}

The contact theory evaluates the effects of permanent contact on the mechanism; this theory is determined according to the relationship of the thickness of the cam to the magnitude of the radius of its primary circle, thus classifying cams as axially short if the thickness does not exceed the value of the radius of the primary circle and axially long cams if this condition is not met [3], [15].

According to the cam classification, the stresses experienced by the cam are also classified. In axially short cams there is flat stress while axially long cams experience flat deformation stress [3]. The study model fulfills the characteristic corresponding to an axially short cam, in addition, since the follower is of translation, the mechanism experiences a slip during the rotation of the cam, this slip represents an additional stress overall [16].

The main stresses experienced by the mechanism are determined by the equations (3), (4) y (5).

$$
\begin{gathered}
\sigma_{x}=\sigma_{x n}+\sigma_{x t} \\
\sigma_{z}=\sigma_{z n}+\sigma_{z t} \\
\tau_{x z}=\tau_{x z n}+\tau_{x z t}
\end{gathered}
$$

Considering that for a disc cam mechanism with roller follower the contact zone is represented by a rectangle of width $\alpha$. As [14], [15] put it, the stresses on the surface of the mechanism are calculated by the equations (6) - (8).

For $|x| \leq \alpha$

$$
\sigma_{x n}=-\mathrm{p}_{\max } \sqrt{1-\frac{x^{2}}{\alpha^{2}}}
$$

Else $\sigma_{x n}=0 \quad \sigma_{z n}=\sigma_{x n} \quad \tau_{x z}=0$

$$
\begin{gathered}
\sigma_{x t}=-2 f_{\max } \frac{x}{\alpha} \quad \sigma_{z t}=0 \\
\tau_{x z}=\tau_{x z n}+\tau_{x z t}
\end{gathered}
$$

For $x>\alpha$

$$
\sigma_{x t}=-2 f_{\max }\left(\frac{x}{\alpha}-\sqrt{\frac{x^{2}}{\alpha^{2}}-1}\right)
$$

For $x<-\alpha$

$$
\sigma_{x t}=-2 f_{\max }\left(\frac{x}{\alpha}+\sqrt{\frac{x^{2}}{\alpha^{2}}-1}\right)
$$

The values corresponding to the variables $f_{\max }, a$ y $\mathrm{p}_{\max }$ are determined by the equations (9), (10) y (11):

$$
\begin{aligned}
& f_{\max }=\mu \mathrm{p}_{\max } \\
& \mathrm{p}_{\max }=\frac{2 F_{c}}{\pi \alpha l} \\
& \alpha=\sqrt{\left(\frac{4 F_{c}}{\pi l} \frac{\frac{1-\gamma_{1}^{2}}{E_{1}}+\frac{1-\gamma_{2}^{2}}{E_{2}}}{\frac{1}{R_{1}}+\frac{1}{R_{2}}}\right)}
\end{aligned}
$$

These terms represent the unit tangential force, the maximum pressure exerted in the contact zone and the width of this zone respectively. 
To solve equations (10) and (11) the equation defining the term Fc representing the contact force experienced by the mechanism is introduced. See equation (12).

$$
F_{c}(t): \frac{a m \omega^{2}+\vartheta c \omega+s k+F_{p l}}{\cos \emptyset}
$$

\subsection{Efective stress}

As expressed by [17] and [18], the main stresses can be replaced by a stress that generates the same effects on the mechanism. For the system evaluated in the present study, the Von Mises criterion has been used, according to the equation (13).

$$
\sigma^{\prime}: \sqrt{\sigma_{x}^{2}+\sigma_{z}^{2}-\sigma_{x} \sigma_{z}+3 \tau_{x z}^{2}}
$$

\section{Results and discussion}

The Bézier curves used in the design of the law of displacement of the tracker, are curves of grade 5, 7 and 9. The general shape of each of these is presented by the equations (14), (15) y (16):

Law of curved displacement of Bézier grade 5:

$$
b(u)=L\left[10 u^{3}-15 u^{4}+6 u^{5}\right]
$$

Law of curved displacement of Bézier grade 7:

$$
b(u)=L\left[35 u^{4}-84 u^{5}+70 u^{6}-20 u^{7}\right]
$$

Law of curved displacement of Bézier grade 9

$$
\begin{array}{r}
b(u)=L\left[126 u^{5}-420 u^{6}+540 u^{7}\right. \\
\left.-315 u^{8}+70 u^{9}\right]
\end{array}
$$

Equations (13), (14) and (15) represent the displacement of the tracker function. Deriving these functions, we obtain the equations for the speed, acceleration and over acceleration of the tracker [3], which are shown below. See equations (17)-(22).

Since the overacceleration function is not required to develop the contact theory, only the first and second derivative of the displacement functions are presented. Thus, it has been obtained:

Derived from the law of curved displacement of Bézier grade 5:

$$
\begin{aligned}
b^{\prime}(u) & =\frac{L}{\beta}\left[30 u^{2}-60 u^{3}+30 u^{4}\right] \\
b^{\prime \prime}(u) & =\frac{L}{\beta^{2}}\left[60 u-180 u^{2}+120 u^{3}\right]
\end{aligned}
$$

Derived from the law of curved displacement of Bézier grade 7:

$$
\begin{gathered}
b^{\prime}(u)=\frac{L}{\beta}\left[140 u^{3}-420 u^{4}+420 u^{5}\right. \\
\left.-140 u^{6}\right] \\
b^{\prime \prime}(\mathrm{u})=\frac{L}{\beta^{2}}\left[420 u^{2}-1680 u^{3}+2100 u^{4}\right. \\
\left.-840 u^{5}\right]
\end{gathered}
$$

Derived from the law of curved displacement of Bézier grade 9:

$$
\begin{gathered}
b^{\prime}(u)=\frac{L}{\beta}\left[630 u^{4}-2520 u^{5}+3780 u^{6}\right. \\
\left.-2520 u^{7}+630 u^{8}\right] \\
b^{\prime \prime}(\mathrm{u})=\frac{L}{\beta^{2}}\left[2520 u^{3}-12600 u^{4}\right. \\
+22680 u^{5}-17640 u^{6} \\
\left.+5040 u^{7}\right]
\end{gathered}
$$

The terms $L, \beta$ are the elevation condition of the follower and the rotation angle of the cam for that elevation, the factor is the ratio of rotation angles $u=\theta / \beta$.

By developing Bézier's functions and incorporating the parameters of table 1 into the contact theory, Von Mises' stress present in the mechanism during a working cycle and for each of the three laws of displacement proposed, the effective stress behavior was obtained.

The figure 3 shows a similar behavior in the variation of the effective stress in each one of the curves used, this occurs due to the direct relation between the variables that intervene in the calculation of the stress of Von Mises.

The figure 4 presents the variation of the main stress in relation to the radius of the roller and the primary circle of the cam in the area that experiences greater stresses, it can be seen an inverse relationship between the magnitude of stress and the radius of the primary circle of the cam. 


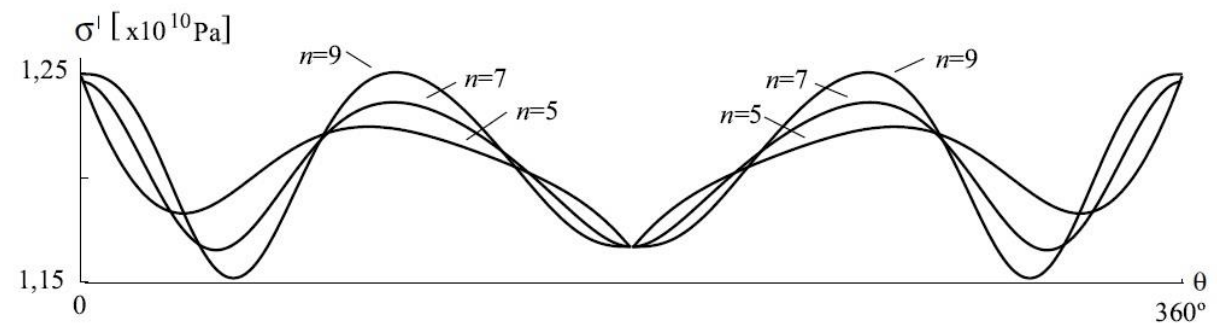

Figure 3. Effective effort in a cam - tracker mechanism designed by means of Bézier curves.

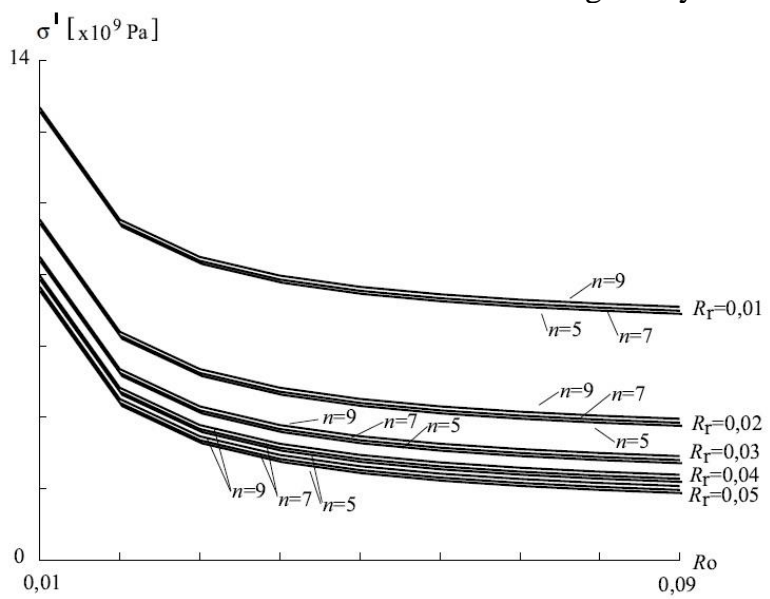

Figure 4. Variation of the stress Von mises for different values of the radius of the primary circle of the cam and the radius of the follower.

\section{Conclusions}

Bézier Curves are very useful for studying the kinematics and dynamics of cams. The design of these mechanisms applying the mathematical model described here is widely favorable because, among other things, Bézier Curves take all the polynomial curves, whether advanced or elementary; they are continuous functions of high order that can easily be derived; and they allow altering the shape of the movement without compromising the limit conditions.

This article presents the variation of the effective stress in a cam-follower mechanism in which the follower displacement law has been designed using Bézier curves. It was determined that the greater the Bézier curve, greater is the magnitude of the effective stress, which would produce a higher probability of component wear.

By analyzing the variation of the effort in the point that experienced greater magnitude of this and varying the values of the radius of the roller and the primary circle of the cam was established an inverse relationship between the stress and the radius of the primary circle of the cam.

\section{References}

[1] R. C. Juvinall, Engineering Considerations of Stress, Strain, and Strength, New York: McGraw-Hill, 1967.

[2] A. Torabi, S. Akbarzadeh, M. R. Salimpour, M. Khonsari, "On the running-in behavior of cam-follower mechanism," Tribology International, vol. 118, pp. 301313, 2018, doi: 10.1016/j.triboint.2017.09.034

[3] C. H. Acevedo Peñaloza, "Estudio del ángulo de presión y de la presión de contacto en mecanismos leva palpador cuya ley de desplazamiento se diseña por curvas de Bézier," tesis doctoral, Universidad Politécnica de Cataluña, Barcelona, 2005.

[4] F. P. Beer, E. R. J. Jonhnston, J. T. DeWolf, D. F. Mazurek, Mecánica de Materiales, México D.F.: McGraw-Hill, 2010.

[5] O. A. González-Estrada, S. Natarajan, C. Graciano, "Reconstrucción de tensiones para el método de elementos finitos con mallas poligonales," Rev. UIS 
Use of Bézier curves in the design of the displacement law of the cam-follower mechanism: Von Mises effective Stress

Ingenierías, vol. 16, no. 1, pp. 23-34, 2017, doi: 10.18273/revuin.v16n1-2017003

[6] T. T. Nga Nguyen, S. Kurtenbach, M. Hüsing, B. Corves, "A general framework for motion design of the follower in cam mechanisms by using non-uniform rational B-spline," Mechanism and Machine Theory, vol. 137, pp. 374-385, 2019, doi: 10.1016/j.mechmachtheory.2019.03.029

[7] M. Shirzadegan, A. Almqvist, R. Larsson, "Fully coupled EHL model for simulation of finite length line cam-roller follower contacts," Tribology International, vol. 103, pp. 584-598, 2016, doi: 10.1016/j.triboint.2016.08.017

[8] C. H. Acevedo Peñaloza, E. Zayas Figueras, S. Cardona Foix, "Introducción al diseño de perfil de levas por Curvas de Bézier," Respuestas, vol. 9, no. 1, pp. 3944, 2004.

[9] G. N. Băsescu, I. V. Crîșmaru, S. I. Strugaru, . C. Paulin, E. S. Bârcă, C. Munteanu, "The Stress Distribution of a Layered Contact Cam Mechanism Using Finite Element," Advanced Materials Research, vol. 837, pp. 316-321, 2014, doi: 10.4028/www.scientific.net/AMR.837.316

[10] H. F. Quintero, L. Vanegas, "Use of the VAP function in the design of cam-follower mechanisms," Ingeniería y Competitividad, vol. 18, no. 2, pp. 207-216, 2016, doi: 10.25100/iyc.v18i2.2169

[11] M. Hidalgo Martínez, E. Sanmiguel Rojas, and M. A. Burgos Olmos, "Design of cams with negative radius follower using Bézier curves," Mechanism and Machine Theory, vol. 82, pp. 87-96, 2014, doi: 10.1016/j.mechmachtheory.2014.08.001

[12] S. C. Foix and D. C. Costa, Teoria de Màquines, Barcelona: Ediciones UPC, 2000.

[13] J. F. Olmedo Salazar, E. A. Vasconez Endara, B. H. Culqui Culqui, M. T. Piovan, "Aplicación de Curvas de Bézier en el diseño y optimización de levas para alta velocidad," Ciencia, vol. 20, no. 2, pp. 144 -159, 2018, doi: 10.24133/ciencia.v20i2.1212

[14] R. L. Norton, Cam design and manufacturing handbook, New York: Industrial Press, Inc., 2009.

[15] S. P. Timoshenko and J. N. Goodier, Theory of Elasticity, New York: McGraw-Hill, 1970.
[16] M. Dežman and A. Gams, "Rotatable cam-based variable-ratio lever compliant actuator for wearable devices," Mechanism and Machine Theory, vol. 130, pp. 508-522, 2018, doi: 10.1016/j.mechmachtheory.2018.09.006

[17] A. Ponter, M. Engelhardt, "Shakedown limits for a general yield condition: implementation and application for a Von Mises yield condition," European Journal of Mechanics - A/Solids, vol. 19, no. 3, pp. 423 - 445, 2000, doi: 10.1016/S0997-7538(00)00171-6

[18] C. Acevedo Peñaloza, S. Ramón Ramón, G. Prada Botia, "Comparison of the Concentration Factor of Stresses on Flat Sheets with Two Holes with Low and High Speed Voltage Test," Contemporary Engineering Sciences, vol. 11, no. 55, pp. 2707 - 2714, 2018, doi: $10.12988 /$ ces. 2018.86288 